\title{
Guaifenesin and increased sperm motility: a preliminary case report
}

This article was published in the following Dove Press journal:

International Journal of General Medicine

20 December 2010

Number of times this article has been viewed

\section{Gary Means' \\ Cristóbal S Berry-Cabán ${ }^{2}$ \\ Kurt Hammermeuller' \\ 'Department of Family Medicine, ${ }^{2}$ Department of Research, Womack Army Medical Center, Fort Bragg, NC, USA}

Correspondence: Cristóbal S

Berry-Cabán

Department of Research, Womack Army

Medical Center, Fort Bragg,

North Carolina, USA 28301

Tel/Fax + I 0I I-910-907-8844

Email: cris.berrycaban@us.army.mil
Background: A review of the literature and an extensive Medline search revealed that this is the first case report of the use of guaifenesin to increase sperm motility.

Case: A 32-year-old male presented for an infertility evaluation. He reported an inability to conceive with his wife after 18 months of unprotected intercourse. A semen analysis was performed that included spermatozoa count, liquefaction, morphology, motility, viscosity and volume. Initial results of the semen analysis demonstrated low sperm count and motility. The provider offered treatment with guaifenesin $600 \mathrm{mg}$ extended release tablets twice daily. Two months after guaifenesin therapy the semen analysis was repeated that demonstrated marked improvement in both total sperm count and motility.

Conclusion: Evidence for the effectiveness of guaifenesin is almost entirely anecdotal. Given the mechanism of action of guaifenesin, it is not clear from this case why the patient demonstrated such a large improvement in both sperm count and motility. Additional studies of the effects of guaifenesin on male fertility could yield information of the medication's effect on men with normal or decreased total sperm counts.

Keywords: sperm motility, guaifenesin, infertility, male pregnancy

\section{Background}

There are currently anecdotal reports and popular news media stories on the use of guaifenesin, particularly the brand name product Robitussin ${ }^{\circledR}$ (Pfizer, Inc., New York, NY), for use in treating both male and female infertility. ${ }^{1-4}$ Guaifenesin is an expectorant medication sold over the counter and usually taken by mouth to assist expectoration of phlegm from the airways in acute respiratory tract infections. Its mode of action in treating infertility is not well understood, but it appears to decrease mucus viscosity. ${ }^{5}$ The case presented here discusses the use of guaifenesin in improving male fertility.

\section{Case}

A 32-year-old male patient presented to his primary care provider for an infertility evaluation. The patient is a nonsmoker, who consumes little or no alcohol with no known allergies. A recent screening exam for pulmonary tuberculosis was negative and the patient had recently undergone a required military service physical exam.

He reported an inability to conceive with his wife after 18 months of unprotected, regular intercourse. As part of a routine infertility evaluation a semen analysis was performed that included spermatozoa count, liquefaction, morphology, motility, viscosity and volume (CPT Code 89320). Initial results of the semen analysis demonstrated low sperm count and motility (Table 1). This sample, as well as the follow-up sample, 
Table I Semen analysis laboratory results

\begin{tabular}{lll}
\hline Lab result & January 6, 2009 & March 3, 2009 \\
\hline Motility & $10 \%$ & $61 \%$ \\
Sperm count (million/mL) & 2.4 & 34.7 \\
Viscosity & Normal & Normal \\
Volume $(\mathrm{mL})$ & 4.0 & 4.0 \\
Days of abstinence & 4 & 3 \\
\hline
\end{tabular}

were obtained through masturbation and provided to the lab within 30 minutes of collection.

The patient's primary care provider offered treatment with guaifenesin $600 \mathrm{mg}$ extended release tablets twice daily. The semen analysis was repeated 2 months after initiation of guaifenesin therapy. The repeat semen analysis demonstrated marked improvement in both total sperm count and motility (Table 1). The patient made no other significant lifestyle changes during the treatment course with guaifenesin. At the time of writing, however, the patient's wife had not yet conceived a child.

\section{Conclusion}

This case report describes the semen analysis laboratory results in a male patient who was given guaifenesin. Guaifenesin is a mucolytic agent usually taken orally to assist the expectoration of phlegm from the airways in acute respiratory tract infections. Guaifenesin is a safe medication that is available over the counter. Its use may improve both male and female infertility related to mucus production. Scientific evidence for the effectiveness of guaifenesin is almost entirely anecdotal; a review of medical literature revealed very limited data on use of guaifenesin for infertility. ${ }^{5,6}$ There appeared to be some improvement in a small study without controls of female infertility related to hostile cervical mucus. ${ }^{5}$ Check regards guaifenesin as the simplest but least effective method of improving cervical mucus. ${ }^{7}$ Given the proposed mechanism of action of guaifenesin, it is not clear from this case why the patient demonstrated such a large improvement in both sperm count and motility. Additional study of the effects of guaifenesin on male fertility suggests the need to conduct a more rigorous placebo-controlled clinical trial that could yield information of the medication's effects on men with normal or decreased total sperm counts.

\section{Disclosure}

The authors disclose no conflicts of interest.

\section{References}

1. Fertile Facts: Robitussin does what? Available from: http://fertilefacts. wordpress.com/. Accessed on November 3, 2010.

2. Fertilinet.com: Male Fertility or Infertility. Available from: http://www. fertilinet.com/male.htm. Accessed on November 3, 2010.

3. PR News Now: Guaifenesin or FertileCM for Enhanced Cervical Mucus, 2009. http://www.prnewsnow.com/Public_Release/OB_Or_GYN/ Guaifenesin_or_FertileCM_for_Enhanced_Cervical_Mucus_162162. html. Accessed on November 3, 2010.

4. Weschler T. Taking Charge of Your Fertility, 10th Anniversary Edition: the Definitive Guide to Natural Birth Control, Pregnancy Achievement, and Reproductive Health. Revised edition. New York, NY: Harper Collins; 2002.

5. Check JH, Adelson $\mathrm{HG}, \mathrm{Wu} \mathrm{CH}$. Improvement of cervical factor with guaifenesin. Fertil Steril. 1982;37:707-708.

6. Check JH. Successful pregnancy despite advanced age and elevated serum follicle stimulating hormone levels - a case report. Clin Exp Obstet Gynecol. 2000;27:171-172.

7. Check JH. Diagnosis and treatment of cervical mucus abnormalities. Clin Exp Obstet Gynecol. 2006;33:140-142.
International Journal of General Medicine

\section{Publish your work in this journal}

The International Journal of General Medicine is an international, peer-reviewed open-access journal that focuses on general and internal medicine, pathogenesis, epidemiology, diagnosis, monitoring and treatment protocols. The journal is characterized by the rapid reporting of reviews, original research and clinical studies across all disease areas.

\section{Dovepress}

A key focus is the elucidation of disease processes and management protocols resulting in improved outcomes for the patient.The manuscript management system is completely online and includes a very quick and fair peer-review system. Visit http://www.dovepress.com/ testimonials.php to read real quotes from published authors. 